\title{
IMPROVEMENT IN HARDENING BEHAVIOUR OF MICRO FIBER REINOFRCED CEMENT MORTAR
}

\author{
G. Avinash ${ }^{1}$, SaptarshiSasmal ${ }^{2}$

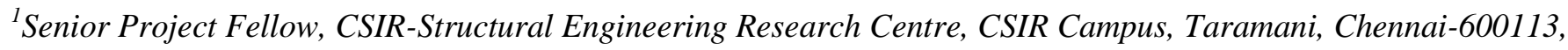 \\ India \\ ${ }^{2}$ Scientist, CSIR-Structural Engineering Research Centre, CSIR Campus, Taramani, Chennai-600113, India \\ *Corresponding Author: Saptarshi Sasmal, Bridge Engineering Group, CSIR-Structural Engineering Research \\ Centre, CSIR Campus, Taramani, Chennai-600113, INDIA. Phone 91-44-22549210; FAX: 91-44-22541508 \\ E-mail: saptarshi@serc.res.in, sasmalsap@gmail.com
}

\begin{abstract}
Synopsis
Concrete is a quasi-brittle material which is weak in tension. Inconsistent behaviour due to excessive heterogeneity, extremely low tensile strength and absence of strain hardening has made the concrete the brittle and fast deteriorating material. It exhibits a tension softening behaviour when subjected to tensile loading. Strain hardening is the property of the material to take up the load even after initiation of crack. Pseudo strain hardening is an induced property which can be achieved through incorporation of the fibers suitable for crack bridging. It involves activation of large number of microcracks that develop normal to tensile loading direction, which results in increase in ductility and damage tolerance of the composite. Pseudo strain hardening behaviour of a cement matrix depends on many parameters such as fiber length, fiber diameter, tensile strength of fiber, Young's modulus of fiber, Young's modulus of matrix, etc. and any change in the above parameters will result in change in the nature of fiber bridging stress with respect to the corresponding crack opening displacement. This behaviour thus relates the microstructural parameters to the mechanical behaviour of the composites. In the present study, improvement in the pseudo strain hardening behaviour due to addition of the micro fibers is studied. Experimental investigations have been carried out to understand the influence of different fiber parameters on the hardening behaviour. The study is useful in understanding the microstructural behaviour of fiber reinforced cement matrix and serves as a tool to progress further towards developing damage resilient concrete with greater durability and ductility.
\end{abstract}

$* * *$

\section{INTRODUCTION}

Cement based materials such as concrete and mortar are the most widely used materials in the field of construction. Many advancements in the production technologies of cement have taken place depending upon the requirement by the users. Reinforced concrete is the most common composite that is abundantly used in the field of construction at present. Concrete when reinforced with steel results in improved performance but the service life is still a concern due to the formation of cracks in the concrete cover and corrosion of steel reinforcement. Concrete being a very brittle material, it is very difficult to restrict the development of cracks. The important material characteristic for which concrete is designed is its compressive strength. Concrete, with tensile strength only $8-15 \%$ of its compressive strength, when subjected to tensile loading, will result in development of cracks at very early stage followed by sudden loss of load carrying capacity ${ }^{1}$. This has made concrete prone to severe damage during earthquakes and results in catastrophic failure of the structure leading to loss of people and property. Studies to reduce the brittleness of the concrete has been vastly carried out by many researchers for decades and it is observed that addition of fibers will improve the fracture toughness and energy absorption capacity of the composite which prevents the structure from undergoing catastrophic failure ${ }^{2,3}$. The result being a modified mode of failure from brittle to quasi brittle post peak tension softening behavior as shown in figure $1 \mathrm{a}$. Apart from the improved fracture toughness, the objective of the researchers is to make the brittle cement composites behave like metallic materials (to a possible extent) which exhibit strain hardening behaviour.

Strain hardening is the ability of the material or composite to take up load even after reaching the yield point. It is a characteristic property of the ductile materials. In brittle cement composites, the above property can be induced by adding fibers and is termed as pseudo strain hardening ${ }^{4-6}$. Pseudo strain hardening in brittle composites is associated with development of micro cracks that develop normal to the loading direction. The brittleness of the composite is distinctly exposed when it is subjected to tension or bending. When a cement composite is subjected to tensile loading, cracks start to develop once its tensile strength is reached and the composite will fail soon. When fibers are added, they bridge the cracks together and act as source to transfer the load through their interface back into the matrix. This takes place until the fiber reaches its tensile strength. When adequate number of fibers are present, i.e if the fiber volume fraction is more, then it can transfer more load as more number of fibers will be present at the crack plane, and the matrix may crack again. This process continues until the matrix fails due to development of many sub-parallel cracks 
with approximately equal crack spacing. The pseudo strain hardening results in composite strain capacity many times more than the matrix strain capacity and the significance of this behaviour is that it can take up load even after the development of the cracks ${ }^{1}$.

The inducing of pseudo strain hardening behaviour in brittle cement composites requires careful selection of microstructural parameters like fiber length, fiber diameter, tensile strength of fiber, Young's modulus of fiber, Young's modulus of matrix, etc. and any change in the above parameters will result in change in the nature of fiber bridging stress with respect to the corresponding crack opening displacement. This behaviour thus relates the microstructural parameters to the mechanical behaviour of the composites. In the present study, improvement in the pseudo strain hardening behaviour due to addition of the micro fibers is studied. Experimental investigations are carried out to understand the influence of different fiber parameters on the hardening behaviour.

\section{FIBER MATRIX INTERFACE}

The interaction between the fibre and matrix is the fundamental property that affects the performance of fiber reinforced composites and its understanding is essential for obtaining the pseudo strain hardening behaviour. Condition of the matrix (un-cracked or cracked), matrix composition, fibre type, geometry and volume fraction, surface characteristics of fibre, relative stiffness between matrix and fibre, orientation of the fibre, rate of loading, and durability of the fibre in the composite are the major parameters affecting the fibre interaction with the matrix. A fiber reinforced composite when subjected to tension or bending, will have stresses and deformations in it. These stresses are transferred along the length of the fibre from the matrix which is due to the difference in stiffness between matrix and the fibre. The deformation at and around the fibre will depend on whether the stiffness of fibre is greater or lesser than the matrix.As the load increases, the chemical bond (Gd) between the fibre and the matrix will be broken first and slippage of fibre starts to take place, which is governed by interface frictional stress $(\tau 0)$. The fibre slowly pulls out during this stage (slip hardening stage), which is accompanied by fibre delamination. i.e. fibre is shaved in to sharp tip at the embedded end. Both chemical bond and interface frictional stress thus play a significant role on the overall behaviour of the composite.

The composite behaviour is usually evaluated through the macro mechanical testingand the tests results have verified the existence of energy dissipation mechanisms in fiber reinforced composites, but they do not explain the origin of this behaviour.7The understanding of the origin of this behaviour can lead us to predict the composite behaviour (by knowing the properties of the matrix, fiber and the interface). With this, the desired output (pseudo strain hardening) can be obtained by suitable selection of the microstructural properties.

\section{COMPLIMENTARY ENERGY}

In brittle cement composites, pseudo strain hardening behaviour is attained by sequential development of micro cracks and for this to happen steady state crack propagation must prevail. To attain this multiple cracking phenomenon, a micromechanical model provides an opportunity to tailor the micro-parameters and thus control the failure mode, tensile strength and ultimate tensile strain of the composite8. A typical bridging stress versus crack opening displacement $(\sigma$ - $\delta$ ) curve for a strain hardening cementitious composite is shown in Figure 1b. For steady state cracking to occur, crack tip toughness jtipshould be less than complementary energy $\mathrm{Jb}$ ' which is calculated from the bridging stress $\sigma$ versus crack opening $\delta$ curve 9,10 . The primary conditions for the pseudo strain hardening behaviour are explained below1,11

$$
\begin{aligned}
& \mathrm{J}_{\text {tip }} \leq \sigma_{\mathrm{o}} \delta_{\mathrm{o}}-\int_{0}^{\delta_{\mathrm{o}}} \sigma(\delta) \mathrm{d} \delta \equiv \mathrm{J}_{\mathrm{b}}{ }^{\prime} \\
& \mathrm{J}_{\text {tip }}=\mathrm{K}_{\mathrm{m}}{ }^{2} / \mathrm{E}_{\mathrm{c}} \\
& (2) \sigma_{\mathrm{fc}}<\sigma_{\mathrm{o}}
\end{aligned}
$$

Where $J_{\text {tip }}$ is the crack tip toughness, $\sigma_{\mathrm{o}}$ is the maximum bridging stress corresponding to the opening $\delta_{o}$ and $E_{c}$ is the composite elastic modulus, $\mathrm{K}_{\mathrm{m}}$ is the matrix fracture toughness and $\sigma_{\mathrm{fc}}$ is the first crack strength.

The area under the curve shown in Figure $1 \mathrm{~b}$ is nothing but the energy consumed due to fiber bridging action per unit crack advance. It is called as fracture energy and is the source of ductility in normal fiber reinforced composites which exhibit tension softening post peak behaviour. But for the present case, complementary energy Jb', which is the net energy available for crack propagation as explained in eq. (1)is considered as the source of ductility. It implies that the maximum energy available for steady state crack propagation should exceed the necessary energy required to break down the matrix.High complementary energy is favourable to multiple cracking and high ductility of the composite. Eq. (3) implies that the first crack strength should not be more than the maximum bridging stress of the fibre, otherwise micro-cracks won't develop as the fibre would have already lost its bridging capacity and composite would fail like a normal fiber reinforced concrete. Thus eqs. (1) and (3) are the ones that are responsible for strain hardening behaviour, without which normal tensile softening behaviour will be obtained. Based on eq. (1) and (3), two performances were proposed to describe the tensile strain hardening behaviour of Engineered Cementitious Composites 12. The performance indices $\sigma_{\mathrm{o}} / \sigma_{\mathrm{fc}}$ (stress performance index) and $\mathrm{J}_{\mathrm{b}}^{\prime} / \mathrm{J}_{\text {tip }}$ (energy performance index) should exceed unity in order obtain micro cracks and pseudo strain hardening behaviour. As complimentary energy and pseudo strain hardening behaviour go hand in hand, the significance of each on the composite post peak behaviour is understood by carrying out experimental investigation using polymer fiber. 


\section{EXPERIMENTAL PROGRAM}

\subsection{Materials and mix proportions}

The basic mixture ingredients are: Ordinary Portland cement grade 53; silica sand (S); and polycarboxylate based high range water reducing admixture (HRWRA). Polymer fiber (Figure $2 \mathrm{a}$ ) of $8 \mathrm{~mm}$ length and $15 \mu \mathrm{m}$ diameter are used in the present study. The properties of polymer fiber used in the study are shown in table 1. In order to maintain low matrix toughness, silica sand with the size ranging between 100 to 250 microns is used for the study. The casting and finishing images are shown in Figure $2 b$ and $2 c$. As the objective of the study is to attain pseudo strain hardening, the fiber volume fraction is set to an optimum value of $2 \%$. The above selection of materials is done based on the reference of previous investigations which have produced good strain hardeningproperties8.

In total, six different mixtures with three different water to cement ratios $(0.4,0.35$, and 0.3$)$ are considered. The details of the mix are shown in table 2.The first three mixtures are non-fiber silicasand mixtures (control specimens) which are used to understand the significance of polymer fiber incorporated cementitious composite. High range water reducer is added until the desired workability is obtained.

\subsection{Specimen Preparation and testing}

Hobart mixer is used for the preparation of mixtures. Three types of tests are carried out. For evaluating the compressive strength, cylinder compressive strength and flexural strength of the composite, specimens using $50 \mathrm{~mm}$ cube, $50 \times 100$ $\mathrm{mm}$ cylinders and 160 x 40 x $40 \mathrm{~mm}$ prisms are, respectively,cast. All the specimens are demolded after 24 hours andkept in water for 28 days curing. Cube compression and cylinder compression strength tests are carried out in Compression Testing Machine (CTM) of 3000 $\mathrm{kN}$ capacity at a loading rate of $200 \mathrm{~N} / \mathrm{s}$. Three point bending test for the determination of flexural strength is carried out in low capacity servo-hydraulic universal testing machine (UTM) of $25 \mathrm{kN}$ capacity under displacement control. The loading rate for the flexural strength tests was kept as $0.05 \mathrm{~mm} / \mathrm{min}$. Figure $3 \mathrm{a}$ shows the image of the composite while being subjected to bending. The mid span deflection is measured using linear variable differential transducer (LVDT).

\section{RESULTS AND DISCUSSION}

\subsection{Compressive Strength}

The average compressive strength test results of the cube and cylinder specimens are shown in table 3. From the table, it is clear that lower the water cement ratio, higher is the compressive strength. The same trend is observed for both cube and cylinder specimens. After the addition of fibers, compressive strength is further increased, but the trend remains the same. The highest value of compressive strength is observed for fiber reinforced composite with a water cement ratio of 0.3 .

\subsection{Flexural Strength}

The polymer fiber is predominant in improving the flexural strength of the composite, as the flexural strength of the fiber specimens is more when compared to non-fiber specimens as shown in table 4 and Figure $4 \mathrm{a}$ and $4 \mathrm{~b}$. Among the fiber specimens, the flexural strength is reduced significantly for specimens with $\mathrm{w} / \mathrm{c}=0.4$, whereas for 0.35 and $0.3 \mathrm{w} / \mathrm{c}$ ratio, the difference in the flexural strength value is less. Since good flexural strength doesn't guarantee good post peak behavior (particularly important for seismic and other high energy loading), the following parameters (first crack strength, deflection at first crack strength, post peak strength, deflection at post peak and deflection at the tail) are calculated from the flexural strength versus deflection graph for the polymer fiber incorporated specimens shown in figure 5(a), 5(b) and 5(c) and values are shown in table 5. These parameters calculated from the graphs provide a clear picture about the post peak behaviour for different $\mathrm{w} / \mathrm{c}$ ratios.

It is significant to note that higher water cement ratio ensures a distinct peak corresponding to first crack because increase in water provides better chemical bond which snaps due to bending. When water cement ratio is less, total pull out is more dependent on frictional force than from chemical bond. Hence, the load drop due to first crack is not found (as overcoming the frictional stress) in specimens with w/c 0.3 , and consistently clearer with 0.35 and 0.4 . Peak stress is higher than the first crack loading when water cement ratio is more. This is because after snapping of chemical bond, the frictional stress helps to build up the strength in fiber before pull out. It is an important observation as, for concrete when strain hardening is desired, higher water cement ratio (provides both chemical bond and friction stress) is required. Other case, when strength is only important (without post crack initiation behaviour) lesser water cement ratio is recommended.It is interesting to note that when water cement ratio is varied from 0.3 to 0.4 , gain of absolute strength shifts from first crack to post crack. Hence, lesser water cement ratio may provide high strength but, the ductility could not be achieved. Whereas, higher water cement ratio activates the chemical fibers, hence, strain hardening is achieved.

As complimentary energy is also an important parameter in attaining pseudo strain hardening behavior, the complimentary energy for all the mixes are calculated using eq. (1). In the present study, complimentary is calculated by taking the post peak stress in order to maintain uniformity in the values.This study also brings one more significant observation that alone complementary energy may not be always provide the clear information for deciding the suitability of concrete for higher ductility. When the lesser water cement ratio is used, no first crack peak is found and hence the energy is calculated till the peak strength. So, high complementary energy is found for both lowest water cement ratio (0.3) and highest water cement ratio (0.4) due to two different reason. That is, first the higher area is considered till the peak load is achieved due to absence of load for first crack in $\mathrm{w} / \mathrm{c}=0.3$, the second case shows higher area due to true delay in peak strain. Hence, it is suggested that both the energy and complementary energy 
are to be taken into consideration for the ductile behaviour of concrete. The cracked surface and microscopic image of the cracked surface is shown in figure $6 \mathrm{a}$ and $6 \mathrm{~b}$. The microscopic image explains the bridging action of the fiber.

\section{CONCLUSION}

An experimental investigationusing polymer fiber to understand itsinfluence on the hardening behavior has been presented in this study. The following conclusions can be made:

- Compressive strength and flexural strength has increased with the addition of the fibers.

- Higher flexural strength doesn't guarantee better ductility.

- Specimens with higher water to cement ratio (0.4) showed better post peak behaviour than 0.35 and 0.3 w/c, but the flexural strength was lesser for $0.4 \mathrm{w} / \mathrm{c}$ than 0.35 and 0.3 . This clearly explains the fact that in order to get better ductility, flexural strength has to be compromised.

- High complementary energy is found for both lowest water cement ratio (0.3) and highest water cement ratio (0.4) due to two different reason. That is, first the higher area is considered till the peak load is achieved due to absence of load for first crack in $\mathrm{w} / \mathrm{c}=0.3$, the second case shows higher area due to true delay in peak strain.

- Hence, it is suggested that both the energy and complementary energy are to be taken into consideration for the ductile behaviour of concrete. The study brings out that with thorough understanding, cement system with tailored properties (such as strength, ductility, complementary energy, delay of first crack, displacement at peak stress) can be developed. Further studies are being carried out by the present authors to develop resilient concrete with desired properties by exploiting the micromechanics of fibermatrix.

\section{REFERENCES}

[1] Collepardi M. The New Concrete, Prima edizione, Tintoretto 2006, P 421.

[2] ACI 544.1-96, 1996. State of the Art Report on Fiber Reinforced Concrete, American Concrete Institute.

[3] Arisoy, B. 2002, "Development and fracture evaluation of high performance fiber reinforced lightweight concrete", Wayne State University.

[4] Wittmann, F.H., "Specific Aspects of Durability of Strain-Hardening Cement-Based Composites," Restoration of Buildings and Monuments, V.12, 2006, pp. 109-118.

[5] Boshoff, W.P., and Van Zijl, G.P.A.G., "TimeDependant Response of ECC: Characterisation of Creep and Rate Dependenve," Cement and Concrete Research, V. 37, 2007, pp. 725-734.
[6] Li, V.C., "From Micromechanics to Structural Engineering: The Design of Cementitious Composites for Civil Engineering Applications," Journal of Structural Mechanics and Earthquake Engineering, V. 10, 1993, pp. 37-48.

[7] Dassios, K.G., "A Review of the Pull-Out Mechanism in the Fracture of Brittle Matrix Fibre Reinforced Composites" Advanced Composites Letters, 2007, vol. 16, No.1, pp. 17-24.

[8] Li, V.C., Wang, S. and Wu, C., Tensile Strain Hardening Behavior of PVA-ECC, ACI Materials Journal, 2001, Vol. 98, No. 6, pp. 483-492.

[9] Marshall, D.B., and Cox, B.N., A J-Integral Method for Calculating Steady-State Matrix Cracking Stresses in Composites, Mechanics of Materials, 1998, Vol. 8, pp.127-133.

[10]Li, V.C., and Leung, C.K.Y., Theory of Steady State and Multiple Cracking of Random Discontinuous Fiber Reinforced Brittle Matrix Composites, Journal of Engineering Mechanics, 1992, Vol. 118, No. 1, pp. 2246-2264.

[11]Leung, C.K.Y., 1996. Design Criteria for Psuedoductile Fiber Reinforced Composites, Journal of Engineering Mechanics, ASCE, 1996, Vol. 22, No. 1, pp. 10-14.

[12] Kanda, T. and Li, V.C., 2006. Practical Design Criteria for Saturated Pseudo Strain Hardening Behavior in ECC, Journal of Advanced Concrete Technology, 4(1), pp. 59-72.

\section{Acknowledgement}

This paper has been published with the kind permission of the Director, CSIR-SERC, Chennai, India. 


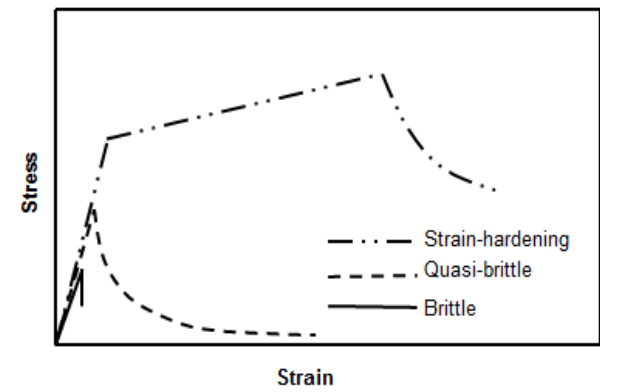

Figure 1a - Types of failure modes in concrete

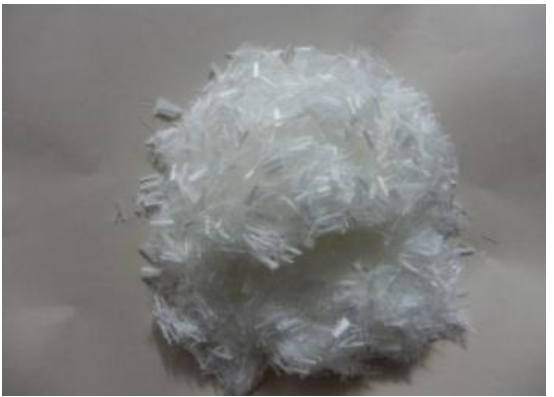

Figure 2a. Polymer fiber used

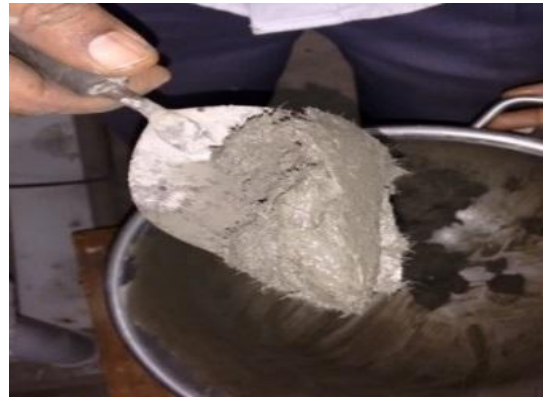

Figure 2b. Composite after mixing

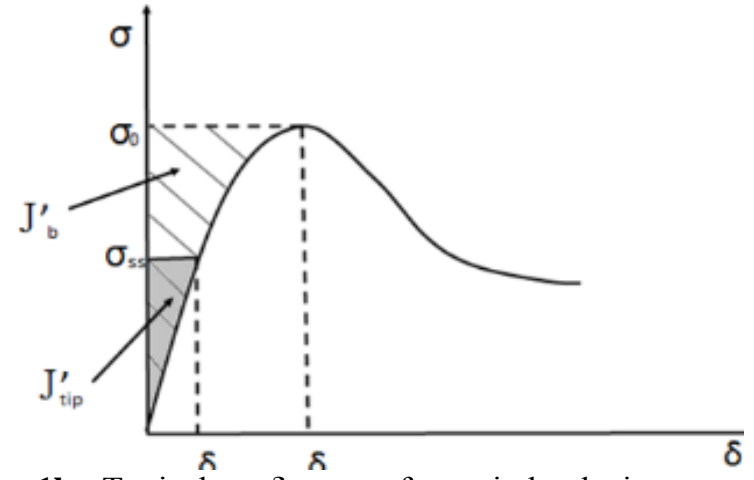

Figure 1b - Typical $\sigma-\delta$ curve of a strain hardening cementitious composite $^{1}$

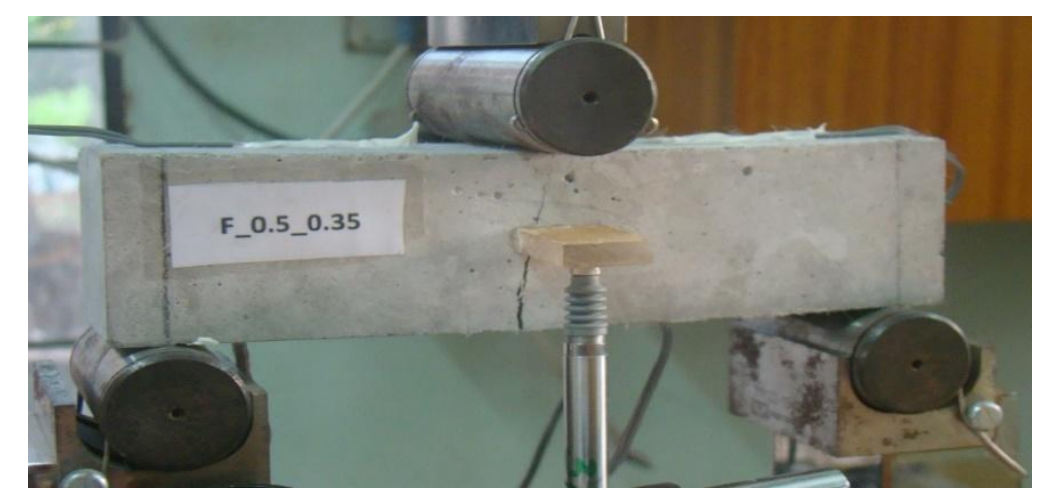

Figure 3 - Fiber incorporated specimen with 0.35 w/c (after reaching first crack strength) being subjected to three point bending.

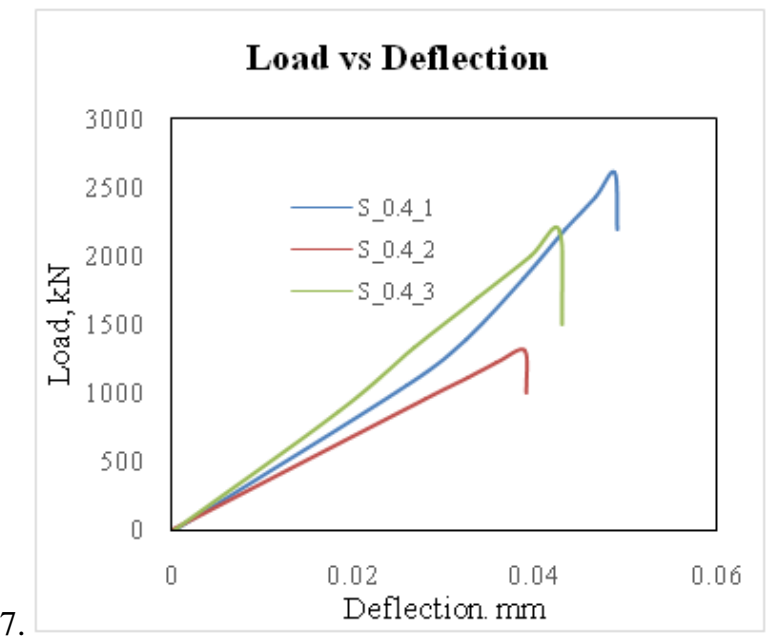

Figure 4a. Load versus deflection for control specimen of $0.4 \mathrm{w} / \mathrm{c}$

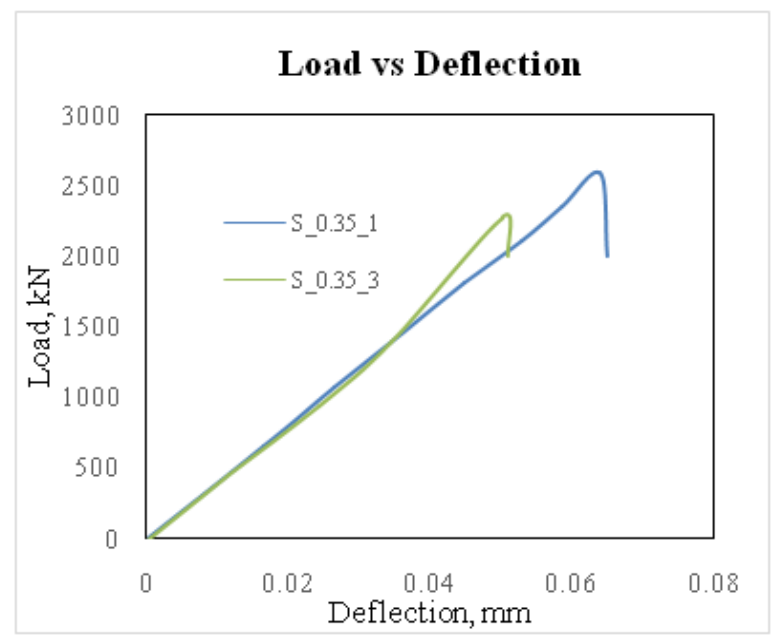

Figure 4b. Load versus deflection for control specimen of $0.35 \mathrm{w} / \mathrm{c}$ 


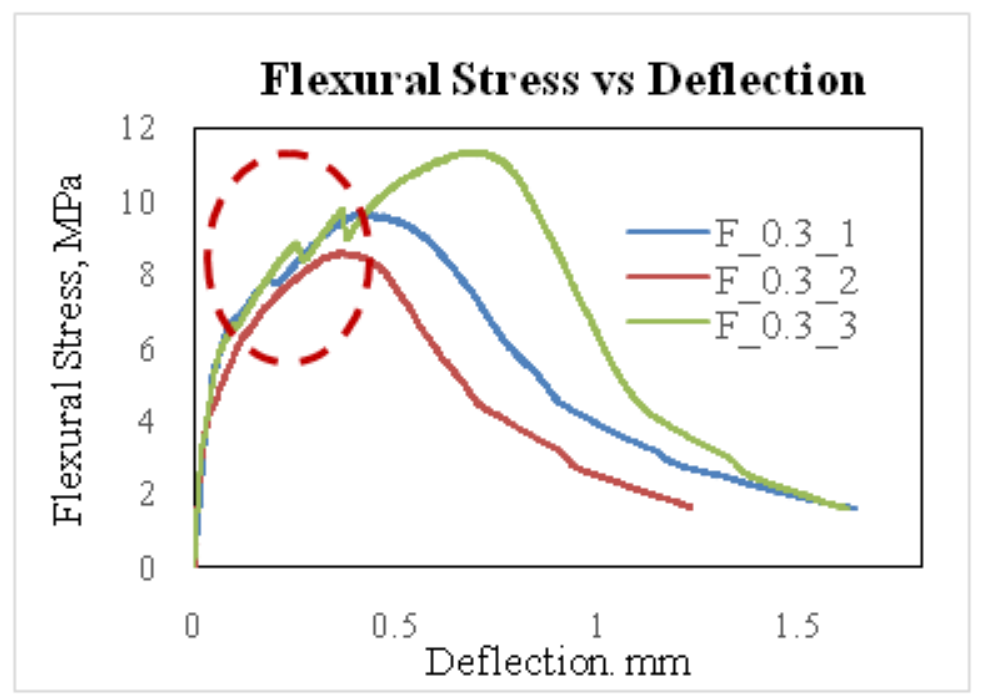

(a)

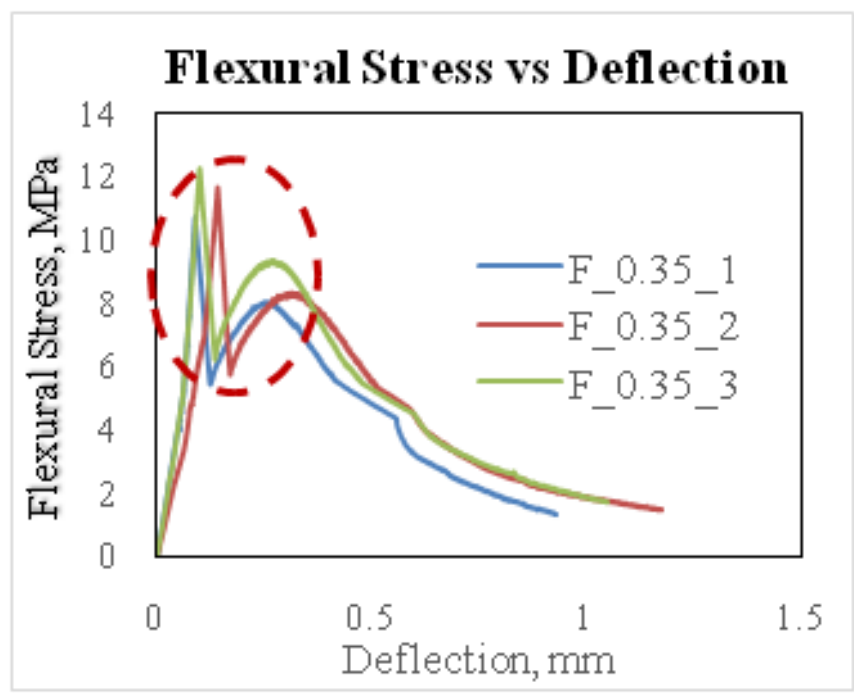

(b)

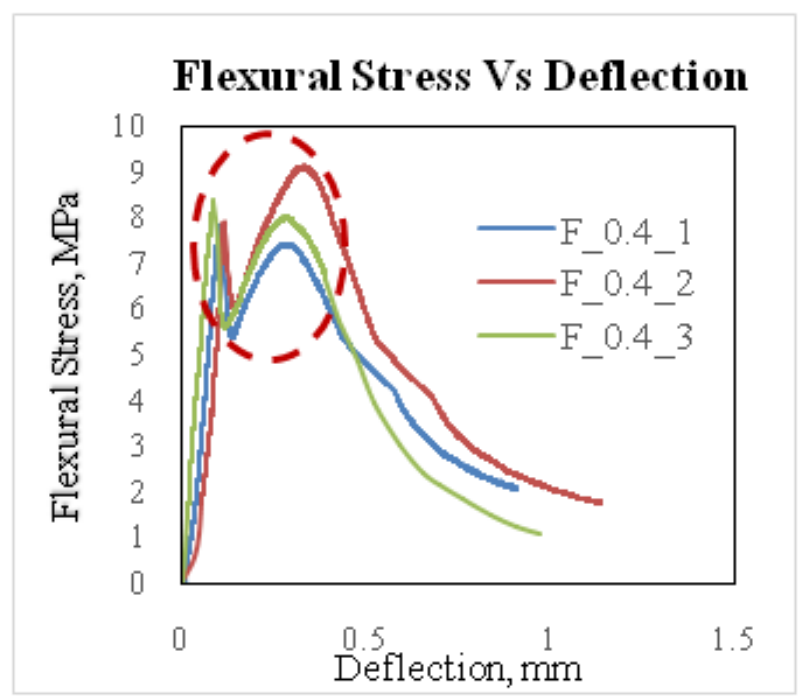

(c)

Figure 5-(a),(b)\&(c) showing the flexural stress versus deflection graph of polymer fiber incorporated specimens for water to cement ratios $0.3,0.35$ and 0.4 respectively.

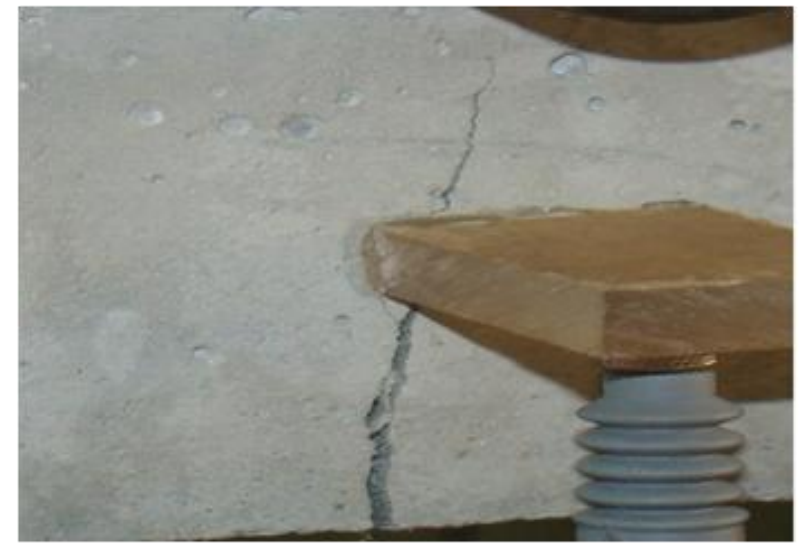

Figure 6a. Cracked surface of the fiber specimen

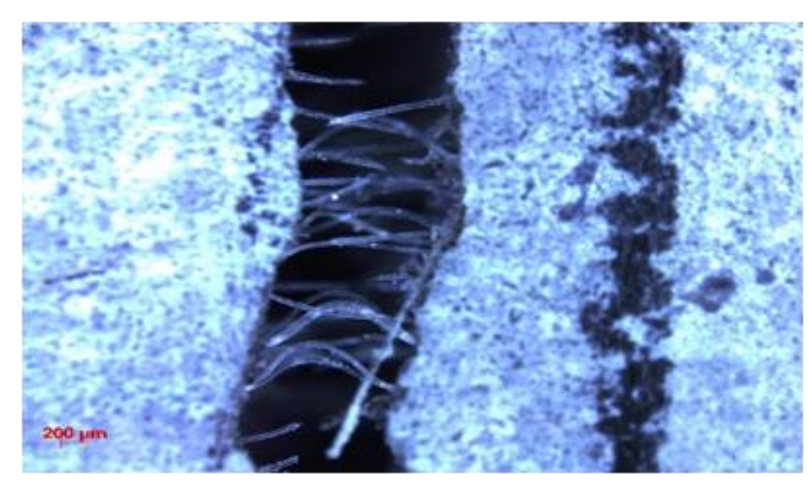

Figure 6b. Microscopic image of the cracked surface 
Table 1 - Properties of polymer fiber

\begin{tabular}{|c|c|c|c|c|}
\hline Fiber Type & $\begin{array}{c}\text { Fiber diameter, } \\
\boldsymbol{\mu m}\end{array}$ & $\begin{array}{c}\text { Fiber length, } \\
\mathbf{m m}\end{array}$ & $\begin{array}{c}\text { Tensile Strength, } \\
\mathbf{M p a}\end{array}$ & Elongation (\%) \\
\hline Short fiber & 15 & 8 & 1560 & 6.5 \\
\hline
\end{tabular}

Table 2 -Mixture proportions by weight

\begin{tabular}{|c|c|c|c|c|c|c|}
\hline S.No & Mix ID & Cement & W/C & S/C & $\begin{array}{c}\left(\mathbf{V}_{\text {f }}\right) \\
\text { volume \% }\end{array}$ & $\begin{array}{c}\text { High range water reducer } \\
\text { (HRWR) }\end{array}$ \\
\hline 1 & S_0.3 & 1 & 0.3 & 0.5 & - & 0.0018 \\
\hline 2 & S_0.35 & 1 & 0.35 & 0.5 & - & 0.0012 \\
\hline 3 & S_0.4 & 1 & 0.4 & 0.5 & - & - \\
\hline 4 & F_0.3 & 1 & 0.3 & 0.5 & 2 & 0.0018 \\
\hline 5 & F_0.35 & 1 & 0.35 & 0.5 & 2 & 0.0012 \\
\hline 6 & F_0.4 & 1 & 0.4 & 0.5 & 2 & - \\
\hline
\end{tabular}

Table 3 - Compressive strength test results

\begin{tabular}{|c|c|c|}
\hline \multirow{2}{*}{ Mixture ID } & \multicolumn{2}{|c|}{ Compressive Strength, MPa } \\
\cline { 2 - 3 } & Cube & Cylinder \\
\hline S_0.4 & 64.18 & 45.93 \\
\hline S_0.35 & 70.48 & 45.32 \\
\hline S_0.3 & 73.86 & 51.16 \\
\hline FS_0.4 & 69.98 & 51.19 \\
\hline FS_0.35 & 74.21 & 52.69 \\
\hline FS_0.3 & 83.37 & 67.93 \\
\hline
\end{tabular}

Table 4 - Flexural Strength of fiber and control specimens.

\begin{tabular}{|c|c|}
\hline Mixture ID & Flexural Strength (MPa) \\
\hline S_0.3 & 4.67 \\
\hline S_0.35 & 8.10 \\
\hline S_0.4 & 7.85 \\
\hline F_0.3 & 10.53 \\
\hline F_0.35 & 11.56 \\
\hline F_0.4 & 8.44 \\
\hline
\end{tabular}

Table 5 - Flexural strength test results

\begin{tabular}{|c|c|c|c|c|c|c|}
\hline Mix ID & $\begin{array}{c}\text { First crack } \\
\text { strength, } \\
\sigma_{\mathrm{f}}(\mathrm{MPa})\end{array}$ & $\begin{array}{c}\text { Deflection } \\
\text { at } \sigma_{\mathrm{f}}, \delta_{\mathrm{f}} \\
(\mathrm{mm})\end{array}$ & $\begin{array}{c}\text { Post peak } \\
\text { strength, } \sigma_{\mathrm{p}} \\
(\mathrm{MPa})\end{array}$ & $\begin{array}{c}\text { Deflection } \\
\text { at } \sigma_{\mathrm{p}}, \delta_{\mathrm{p}} \\
(\mathrm{mm})\end{array}$ & $\begin{array}{c}\text { Deflection } \\
\text { at tail, } \delta_{\mathrm{t}} \\
(\mathrm{mm})\end{array}$ & $\begin{array}{c}\text { Complimentary } \\
\text { Enegy, } \mathrm{J}_{\mathrm{b}} \\
\left(\mathrm{J} / \mathrm{m}^{2}\right)\end{array}$ \\
\hline F_0.3_1 & - & - & 9.70 & 0.415 & 1.616 & 0.9207 \\
\hline F_0.3_2 & - & - & 8.59 & 0.366 & 1.231 & 0.727 \\
\hline F_0.3_3 & - & - & 11.34 & 0.685 & 1.611 & 1.76 \\
\hline F_0.35_1 & 10.757 & 0.087 & 8.03 & 0.264 & 0.852 & 0.456 \\
\hline F_0.35_2 & 11.668 & 0.143 & 8.273 & 0.312 & 1.102 & 0.64 \\
\hline F_0.35_3 & 12.28 & 0.101 & 9.36 & 0.273 & 1.045 & 0.61 \\
\hline F_0.4_1 & 7.82 & 0.098 & 7.423 & 0.267 & 0.91 & 0.56 \\
\hline F_0.4_2 & 7.88 & 0.1122 & 9.12 & 0.33 & 1.037 & 1.044 \\
\hline F_0.4_3 & 8.37 & 0.084 & 8 & 0.275 & 0.7 & 0.505 \\
\hline
\end{tabular}

